\title{
Oral Ulcers Associated with Scrub Typhus
}

\author{
Shotaro Suzuki ${ }^{1}$ and Lisa Hirahara ${ }^{2}$
}

Key words: Orientia tsutsugamushi, scrub typhus, oral ulcer, sore throat

\section{(Intern Med Advance Publication) \\ (DOI: 10.2169/internalmedicine.7037-21)}

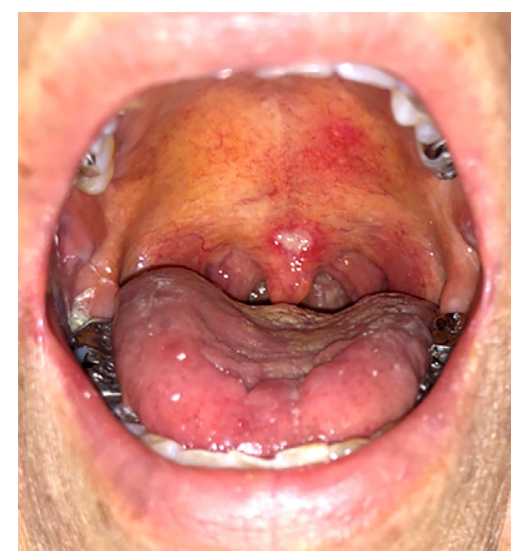

Picture A.

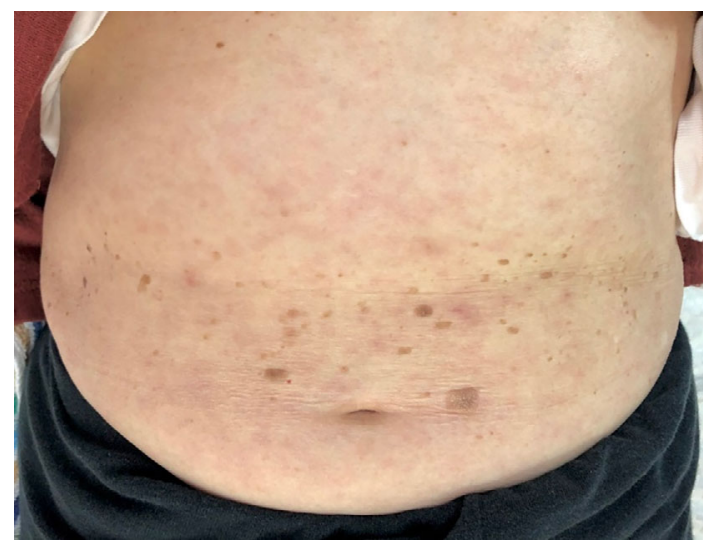

Picture C.

A previously healthy 71-year-old woman presented with a 5-day history of worsening myalgia, sore throat, oral ulcers and a low-grade fever. Her primary care physician suspected rheumatic diseases, so she was referred to our hospital. A physical examination revealed nonpruritic maculopapular rashes on the trunk and extremities and painful mucosal ul-

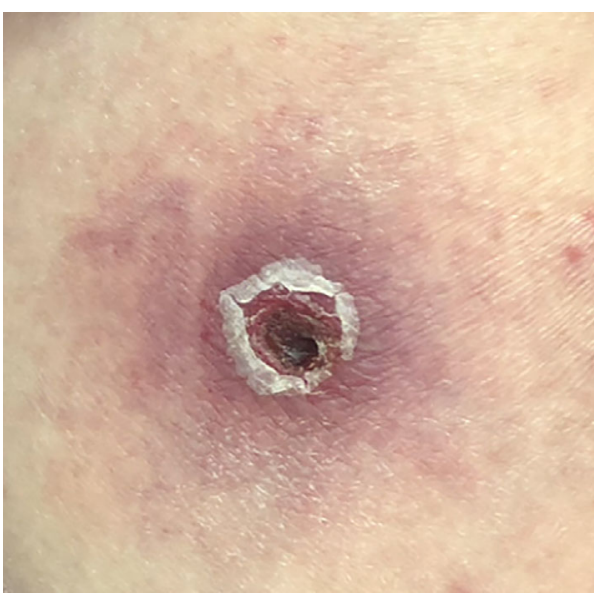

Picture B.

ceration above the uvula (Picture A). A painless black crust (eschar) with central necrosis was present on her left thigh (Picture B), and non-pruritic maculopapular erythema on the abdomen was observed (Picture C). The eschar of her thigh was positive for Orientia tsutsugamushi according to a polymerase chain reaction analysis. Doxycycline $200 \mathrm{mg} /$ day was initiated. After 10 days, her symptoms disappeared. Scrub typhus is a mite-borne infectious disease caused by $O$. tsutsugamushi, which is endemic in Japan. Sore throat may occur (1), although oral ulceration is a rare manifestation, as in our case. Other infectious diseases that cause oral ulceration include herpes simplex virus, varicella-zoster virus (2), human immunodeficiency virus (3), syphilis (4) and tuberculosis (5). Identifying eschars through careful clinical examinations is important, as scrub typhus can mimic other infectious illnesses and rheumatic diseases.

The authors state that they have no Conflict of Interest (COI).

\section{Consent for Case Report}

Shotaro Suzuki (corresponding author) has obtained informed

${ }^{1}$ Division of Rheumatology and Allergology, Department of Internal Medicine, St. Marianna University School of Medicine, Japan and ${ }^{2}$ Department of Stem Cell and Immune Regulation, Yokohama City University Graduate School of Medicine, Japan

Received: January 14, 2021; Accepted: April 25, 2021; Advance Publication by J-STAGE: June 12, 2021

Correspondence to Dr. Shotaro Suzuki, shotaro.suzuki@marianna-u.ac.jp 
consent from the patient. The consent form is kept by the corresponding author.

\section{References}

1. Chang Y-C, Kuo K-C, Sun W, Lin J-N, Lai C-H, Lee C-H. Clinicoepidemiologic characteristics of scrub typhus and murine typhus: A multi-center study in southern Taiwan. J Microbiol Immunol Infect 52: 769-778, 2019.

2. Santosh AR, Muddana K. Viral infections of oral cavity. J Fam Medicine Prim Care 9: 36, 2020.
3. Reichart P. Oral ulcerations in HIV infection. Oral Dis 3 (S1): S 180, 1997.

4. Ficarra G, Carlos R. Syphilis: The Renaissance of an Old Disease with Oral Implications. Head Neck Pathology 3: 195-206, 2009.

5. Sharma S, Bajpai J, Pathak P, Pradhan A, Singh P, Kant S. Oral tuberculosis - Current concepts. J Fam Medicine Prim Care 8: 1308, 2019.

The Internal Medicine is an Open Access journal distributed under the Creative Commons Attribution-NonCommercial-NoDerivatives 4.0 International License. To view the details of this license, please visit (https://creativecommons.org/licenses/ by-nc-nd/4.0/).

(C) The Japanese Society of Internal Medicine Intern Med Advance Publication 